\title{
Entrevista
}

\section{Djamila Ribeiro:}

uma voz para

o nosso tempo

REALIZAÇÃO ${ }^{* 1}$

Christiane Costa de Matos Fernandes |

Deborah Moreira Guimarães | Juliana

Lira Sampaio | Rebeca Furtado de Melo

DOI:10.12957/ek.2019.49903

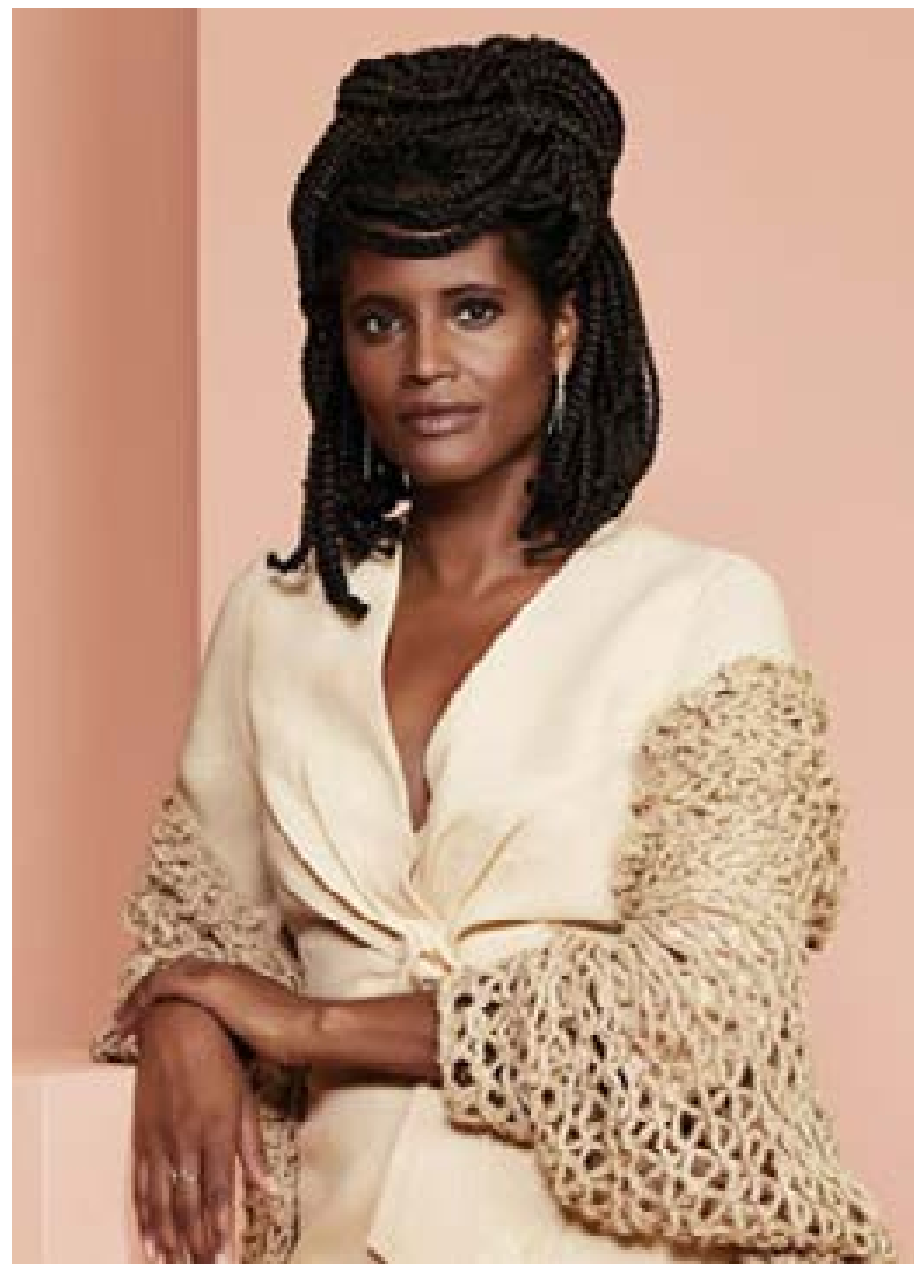

\section{Edição especial para o dossiê "Feminismos"}

Revista Ekstasis: Revista de Hermenêutica e Fenomenologia (V.8, N.2)

\footnotetext{
*1 Esta entrevista foi elaborada por Christiane Costa de Matos Fernandes, Deborah Moreira Guimarães, Juliana Lira Sampaio e Rebeca Furtado de Melo. As perguntas foram enviadas por e-mail à filósofa Djamila Ribeiro, que as respondeu por escrito. Gostaríamos de fazer um agradecimento especial à Djamila, por sua solicitude e gentileza ao aceitar contribuir com o nosso trabalho. É uma alegria e uma honra poder compartilhar suas palavras, tão inspiradoras e necessárias, neste dossiê.
} 
Djamila Ribeiro dispensa apresentações. Porém, temos o prazer de relembrar, na presente ocasião, alguns passos de sua trajetória. Feminista, filósofa e acadêmica não são apenas tags, mas termos que sintetizam sua real importância no Brasil e no mundo. Djamila fala e escreve para a academia, o que a torna uma acadêmica, mas não se restringe ao universo que compõe o mundo acadêmico. Sua presença, sobretudo ao longo dos últimos seis anos, foi tomando conta de muitos outros espaços de diversas formas: redes sociais; jornais; revistas; emissoras de TV etc. Djamila foi além de seu diploma de pesquisadora e professora de filosofia e tornou-se uma filósofa, devido à originalidade e à grande relevância de seu pensamento. Mas, antes de tudo, Djamila é feminista. Sua atividade enquanto filósofa e acadêmica é transpassada pela luta em busca da igualdade de direitos entre homens e mulheres, pelo fim do sexismo e da opressão de gênero, mas que põe em tela a urgência das questões de classe e raça, pensamento indissociável da práxis política que visa o fim de padrões patriarcais e do racismo estrutural e estruturante em prol de uma vivência humana livre de opressões. Sua voz é necessária. Sua voz representa uma luta, pois é verbo vivo do nosso tempo, para o nosso tempo e para o tempo dos que virão.

Djamila Taís Ribeiro dos Santos é graduada em filosofia (2012) pela Universidade Federal de São Paulo e mestra em Filosofia política (2015) pela mesma instituição. Em maio de 2016, foi nomeada secretária-adjunta de Direitos Humanos e Cidadania da cidade de São Paulo, durante a gestão do prefeito Fernando Haddad. Em 2015, escreveu o prefácio do livro até então inédito no Brasil "Mulheres, raça e classe" da filósofa negra e feminista Angela Davis. É autora dos seguintes livros: "Lugar de fala" (2017), "Quem tem medo do feminismo negro?" (2018) e "Pequeno manual antirracista" (2019). Foi indicada ao prêmio Jabuti de Humanidades e agraciada com o prêmio Prince Claus Award 2019, devido à importância de sua produção cultural. Em 2019, foi eleita pela BBC uma das 100 mulheres mais inspiradoras e influentes do mundo.

Natural da cidade de Santos, São Paulo, Djamila iniciou o contato com a militância ainda na infância. Uma das grandes influências foi o pai, estivador, militante e comunista, um homem que mesmo com pouco estudo formal, era culto. "Desde muito cedo, eu e meus dois irmãos vivemos nesse meio. Com seis anos, já íamos para atos. A gente debatia esses temas em casa, e meu pai nos fazia estudar a história do nosso povo", relembra. O movimento feminista entrou na vida da filósofa aos 19 anos, quando conheceu a ONG Casa de Cultura da Mulher Negra, em Santos, onde trabalhou por cerca de quatro anos. Lá, teve contato com obras de feministas e de mulheres negras e passou a estudar temas relacionados a gênero e raça (Revista VICE - 18 de novembro, 2016). 
ENTREVISTA Djamila Ribeiro: Uma voz para o nosso tempo
Christiane C. M. Fernandes | Deborah M. Guimarães | Juliana L. Sampaio | Rebeca F. de Melo

Colunista e autora de textos publicados na CartaCapital, no Blogueiras Negras e na Folha de S. Paulo, Djamila possui forte presença no ambiente digital, onde se tornou uma importante referência do feminismo negro. Contra a estrutura hegemônica de informação que inviabiliza as vozes das mulheres negras, conseguiu usar a internet e os meios digitais para expandir sua voz e levá-la a inúmeros leitores e leitoras, além de ter assumido a tarefa fundamental de publicar, a partir do Selo Sueli Carneiro, casa da Coleção Feminismos Plurais, obras filosóficas e literárias brasileiras e de tradução de produções estrangeiras, sobretudo feita por mulheres, em especial negras, indígenas, LGBTQI+, latinas e caribenhas. Pensadora ativa participa constantemente de eventos, debates, entrevistas e outras ações que envolvam debates de raça e gênero.

\section{Entrevista}

1) No final de 2019, você foi laureada pelo Prince Claus Awards em reconhecimento de sua atuação como uma intelectual pública e foi, além disso, eleita pela BBC como uma das cem mulheres inspiradoras do mundo. Gostaríamos, antes de tudo, de lhe parabenizar e dizer que é um orgulho para nós termos uma representação internacional como a sua, a partir da luta feminista, antirracista e anticolonial. Reconhecemos que nos últimos anos você tem se dedicado a ocupar o espaço público promovendo, de maneira engajada e militante, tais debates filosóficos e políticos, seja como colunista de mídias de grande alcance, como a CartaCapital e a Folha de São Paulo, seja por meio de redes sociais (contando com quase meio milhão de seguidores no Instagram), mas também ocupando cargos públicos como, por exemplo, secretária-adjunta da Secretaria de Direitos Humanos e Cidadania da cidade de São Paulo, na gestão de Fernando Haddad (PT), entre maio e dezembro de 2016. A política, certamente, é uma área fundamental da filosofia, mas nem sempre quem se dedica a ela (muitas vezes, nem mesmo quem se dedica a discutir teoricamente problemas políticos) está disposta e disponíveis para, de fato, ocupar e fazer do espaço público o lugar filosófico por excelência. Na sua opinião, qual é a importância de a filosofia ocupar e disputar o debate público sobre as questões que perpassam nossas existências em um mundo comum e compartilhado e quais são os riscos e/ou soluções que tal posicionamento pode trazer?

Djamila Ribeiro: Bom, primeiro, eu gostaria de agradecer as gentis palavras e todo incentivo para continuar a trajetória, que, olha, não é fácil. Tradicionalmente, 
ENTREVISTA Djamila Ribeiro: Uma voz para o nosso tempo

o cenário do debate público brasileiro foi composto majoritariamente por homens brancos. De acordo com uma pesquisa da Universidade de Brasília (UnB), coordenada por Regina Dalcastagnè, 70\% dos livros publicados no Brasil entre 1965 e 2014 foram escritos por homens. Desse percentual, 90\% são brancos do eixo Rio-São Paulo. Trata-se de uma pesquisa importante para entender que quando falamos em lugar de fala estamos a falar justamente de lugares de apagamento e inexistência, de um lado, enquanto, de outro, há o sequestro do debate e hegemonia plena das vozes em razão da cor, classe, gênero e região geográfica. E o campo do debate público é um desses espaços. Por isso, quando pessoas negras, sobretudo mulheres negras, desafiam essa norma posta, como vêm fazendo há gerações e, por isso, nos últimos anos houve uma ampliação no espaço de debate, o resultado é a transformação desse espaço. E há uma troca muito interessante em curso com o público, que demonstra querer justamente essa mudança. Se formos pensar na Flip, a maior feira literária do país, como exemplo, em 2018, emplaquei dois livros na lista de mais vendidos, na segunda posição com Lugar de Fala e na terceira com Quem tem medo do Feminismo Negro?, ambos atrás somente do livro de Hilda Hilst, homenageada da Feira. Já em 2019, dos 5 mais vendidos nenhum é branco ou branca, sendo Memória da Plantação, de Grada Kilomba, o mais vendido. Lugar de Fala apareceu de novo entre os dez mais vendidos, em $9^{\circ}$ lugar. A Coleção Feminismos Plurais, com, até o momento, oito mulheres e homens negros, ultrapassou a marca de 100 mil cópias vendidas, com milhares de pessoas indo às palestras e resultados que marcam uma geração. A qualificação crítica do público, o interesse em cadeia por leituras de outras vozes negras e a transformação do espaço público de debate serão alguns dos efeitos que vemos e veremos ainda mais com o passar do tempo.

No meu caso, os riscos por essa luta foram, na verdade, a sobrecarga que tive com todo o desgaste mental, físico e espiritual que essa disputa de narrativa constante no espaço público me trouxe. 2019 terminou de uma forma gloriosa, com o Prêmio Prince Claus, mas também foi um ano em que fiz, ao todo, 154 eventos, nas cinco regiões do país e em mais de oito países. Juntam-se a isso os dias necessários para chegar e partir do local do evento, outros dias de trabalhos em livros, artigos e entrevistas, para dimensionarmos o que foi esse ano, sem contar todo o trabalho de rede social. Fiquei muito menos do que gostaria com minha filha e não me dediquei às coisas que gosto de fazer: kung fu, idiomas, ler, ver as pessoas queridas. Foram anos muito importantes, muito trabalho foi feito, mas projeto trabalhar de uma outra maneira daqui para frente. 
ENTREVISTA Djamila Ribeiro: Uma voz para o nosso tempo
Christiane C. M. Fernandes | Deborah M. Guimarães | Juliana L. Sampaio | Rebeca F. de Melo

2) Você possui graduação (2012) e mestrado (2015) em filosofia pela UNIFESP, sua dissertação, intitulada "Simone de Beauvoir e Judith Butler: aproximações e distanciamentos e os critérios de ação política", já indica o campo de questões que mobiliza seu pensamento. Como foi a trajetória entre a formação acadêmica tradicional - por vezes restrita à reprodução exegético-histórica - e a prática intelectual de um pensamento original? De outro modo, como foi o percurso, se for possível dizer nesses termos, entre a Djamila pesquisadora e a Djamila filósofa? Você encontrou alguma resistência na academia nesse processo? Em algumas entrevistas você relembra os primeiros contatos com o movimento negro ainda na infância em Santos (SP) e a influência do pai, estivador, militante e comunista. Você também recorda quando, aos 19 anos, trabalhou na ONG Casa de Cultura da Mulher Negra e se aprofundou no movimento feminista. Como esses caminhos constituíram e mobilizaram seu pensamento? Você acha que a universidade brasileira, de maneira mais precisa, a formação filosófica brasileira, está aberta ou mesmo preparada para pensadores/pesquisadores que transformem suas vivências e militância em prática de pensamento?

Djamila Ribeiro: Nossa, encontrei muitas resistências. Minha trajetória na academia foi uma caminhada solitária, muitas vezes, até a obtenção do Mestrado. Hoje falo abertamente sobre minha dissertação, falo sobre como tive que mentir para ter o projeto aprovado. Falo sem culpa. Passei toda uma graduação sem ter sido me apresentada nenhuma mulher filósofa branca, o que dirá negra. À época que fiz o projeto, falar em feminismo negro seria o mesmo que entregá-lo à reprovação. Então, apresentei que faria o estudo comparativo entre Beauvoir e Butler e, quando foi aprovado, mudei completamente o projeto. Quem lê somente o título pode se surpreender que a maior parte do trabalho é discutir a perspectiva filosófica feminista negra, sobretudo, o pensamento de Audre Lorde. Esse foi apenas um dos episódios da minha vida, na academia, em que tive que jogar capoeira. Veja a capoeira, os senhores de engenho achavam que era uma dança, mas os escravizados sabiam se tratar de uma luta. Ainda na graduação, lembro-me de uma vez que disse ao professor que ministrava aulas de existencialismo francês que gostaria de estudar Beauvoir, ao que ele me respondeu "Beauvoir... quem? A mulher do Sartre?". Beauvoir, que escreveu tanto sobre a categoria do Outro, mostrou-se atual mais uma vez.

Em meio ao desamparo para obter uma orientação para estudá-la, tive a ousadia de escrever um trabalho e submetê-lo ao Congresso da Beauvoir Society, organização internacional que se reúne em Congressos anuais ao redor do mundo para discutir seu pensamento, e, para a minha alegria, o trabalho foi 
ENTREVISTA Djamila Ribeiro: Uma voz para o nosso tempo

aprovado. Só que o Congresso era no Oregon e eu tinha muitas dificuldades financeiras e nem sequer tinha visto estadunidense. Bom, vocês imaginam a luta que foi para chegar lá... Dinheirinho contado, valioso. Cheguei na Universidade de Udine, ainda graduanda, com idioma inseguro, naquele seminário onde só havia doutoras e apresentei na cara e na coragem. Era um trabalho que partia do pensamento beauvoiriano para refletir sobre as "mulheres frutas", muito famosas à época. Nunca vou me esquecer como fui acolhida, os comentários ao trabalho foram muito proveitosos e ganhei dezenas de livros de e sobre Beauvoir que foram fundamentais para minha dissertação. Foi uma alegria muito grande ter conversado com Margaret Simmons, que conviveu com Beauvoir e é uma das maiores autoridades internacionais no tema, mantemos contato até hoje. Dois anos depois, já mestranda, fui de novo ao Seminário, o qual, dessa vez, aconteceu em La Plata, na Argentina.

Então, a trajetória contou com muita ginga, militância e ousadia para estudar o que, na academia brasileira, não era tido como "filosofia", mas que pulsa em outros lugares que não aqui. Beauvoir é apenas um exemplo da grande maioria das pensadoras com as quais trabalho que não foram me apresentadas na academia. No campo internacional, bell hooks, Patricia Hill Collins, Grada Kilomba, Angela Davis, como no campo nacional, como Sueli Carneiro, Lélia González, Conceição Evaristo, Neusa Santos, entre tantas outras, fui conhecê-las na militância, sobretudo na biblioteca Carolina Maria de Jesus, que ficava na Casa de Cultura da Mulher Negra de Santos. Trabalhar com essas pensadoras em cursinhos para a população negra, posteriormente no Núcleo de Raça, Classe e Sexualidade que co-fundei na Unifesp, e que reunia um grupo de estudos de alunos que se organizava para trazer pensadores de fora, foram fundamentais para a trajetória. De outro lado, na academia aprendi a realizar a leitura lógica e o debate filosófico, que é completamente diferente do debate como é posto fora desse espaço. Então, o caminho entre academia e militância ao fim do mestrado não foi, na verdade, uma transição, pois sempre mantive presença nesses espaços.

Penso que ao passo que a academia não questiona por que no quadro de professores há, na grande maioria, homens brancos e poucas mulheres brancas, enquanto os terceirizados da portaria são negros e os da faxina do banheiro são negras, não há muita esperança para a academia brasileira. É importante dizer que justamente por ter sido feito por e para pessoas brancas somente, a presença de pessoas negras nesse espaço é fundamental e somente com ela e com a disputa de narrativa que advém de outros corpos é que é possível transformar esse ambiente e o pensamento que vem sido produzido por ele. 
ENTREVISTA Djamila Ribeiro: Uma voz para o nosso tempo
Christiane C. M. Fernandes | Deborah M. Guimarães | Juliana L. Sampaio | Rebeca F. de Melo

3) Contra a estrutura hegemônica constituinte de grande parte das unidades de informação, você conseguiu usar a internet e os meios digitais para expandir sua voz e levá-la a inúmeros leitores e leitoras. Como foi esse processo? Como você interpreta essa relação entre o pensamento filosófico, conceitual e político e as características e especificidades do debate virtual?

Djamila Ribeiro: Olha, quando estava na Casa de Cultura, e mesmo depois na Unifesp, enfiava o dedo na cara no debate, ficava furiosa. Nos grupos de Facebook, era "das tretas", passava o dia discutindo e, depois de ganhar alguma relevância no debate público, quando comecei a coluna na CartaCapital, muitos, que se incomodaram com uma mulher negra nesse espaço, atacavam-me diariamente, contando ainda com minha atenção. Em certo ponto, fui a um debate e lá estava Sueli Carneiro. Nos bastidores, com a sala cheia, ela entona a voz e determina que todos saiam da sala, menos eu. Me tremi toda, não estava esperando por nada disso. Sueli me segurou pela mão e me deu uma bronca que nunca mais esqueci. Disse que eu tinha que sair de todos os grupos de discussão na internet, que tinha que parar de perder meu tempo com gente pequena e ir cuidar da minha carreira. Foi o que fiz, fechei minha página apenas para amigos e amigas e passei a escrever mais na Carta sobre feminismo negro. As respostas foram vindo com o tempo e me resguardei mais, catalisei toda minha energia para construção e a Coleção Feminismos Plurais e o Selo Sueli Carneiro nasceram disso.

É claro que há todos os limites e distrações, mas penso que as redes sociais foram e são importantes para nós que não tivemos e ainda não temos espaços na mídia hegemônica. Foram as redes que possibilitaram o Blogueiras Negras, que tantas portas abriu para mulheres como eu, entre tantas outras iniciativas, um verdadeiro xirê para o qual a sociedade brasileira branco-patriarcal certamente não estava preparada.

4) Recentemente, você citou em um dos seus textos a pesquisa coordenada pela Professora Regina Dalcastagnè, professora titular de literatura brasileira da UnB que mostrou que, no Brasil, entre 2005 a 2014, 97\% dos livros de literatura foram escritos por autores brancos e $70 \%$ deles, por homens. Na filosofia, o dossiê elaborado pela Professora Carolina Araújo, do departamento de filosofia da UFRJ, mostrou que, nas pós-graduações em filosofia, $80 \%$ das funções docentes são exercidas por homens e que uma mulher possui aproximadamente 2,5 vezes menos chance do que um homem de chegar ao topo dessa carreira profissional. Que saibamos não houve o recorte racial nessa pesquisa, mas podemos projetar 
ENTREVISTA Djamila Ribeiro: Uma voz para o nosso tempo

que os dados também seriam bastante alarmantes. De fato, sabemos que ainda há uma resistência acadêmica colonialista que insiste em não reconhecer outras tradições de pensamento, como a africana, a ameríndia, a hindu, a chinesa etc. como filosofia propriamente dita, e, certamente, ainda não se fala sobre um cânone de pensadoras mulheres, o que faz da filosofia uma repetição constante da voz masculina e branca. A partir da sua vivência enquanto mulher, negra, acadêmica, filósofa e, hoje, co-fundadora de uma linha de pesquisa, quais fatores você considera mais decisivos para a manutenção dessa desigualdade? O que é preciso ser feito para que a filosofia seja mais democrática e plural e possa pensar, daqui para frente, na formação de um núcleo de pensadoras e de filósofos e filósofas historicamente racializados e subalternizados como bibliografia fundamental, para que, cada vez mais, a diversidade de vozes seja levada adiante? Como professoras e pesquisadoras o que você acredita que podemos e devemos fazer para nos comprometer com uma mudança dessa realidade na produção do conhecimento? Quais são os impactos que ela causa nas gerações futuras?

Djamila Ribeiro: As pessoas brancas têm uma característica muito presente: além de dominar os meios de produção, elas se citam o tempo inteiro, se protegem, se premiam, se aplaudem, quando um cai, o grupo já vem socorrê-lo e outro grupo já vem habilitar algum outro branco para o espaço. Essa realidade, cunhada por Cida Bento em sua tese de doutorado como o "pacto narcísico da branquitude", é uma tecnologia do racismo que atua fortemente no ambiente acadêmico. Veja, Narciso, o jovem caçador condenado a se apaixonar somente pela própria imagem, como um mito fundador da branquitude é muito poderoso. Para Narciso, tudo que não é espelho é feio. Para o acadêmico branco narcisista, a filosofia africana, ameríndia, hindu, chinesa e tantas outras não é filosofia porque não se parece com ele. Quanto a Narciso, sabemos bem o fim que ele teve... Isso está dado. Agora, como se combate o regime autorizado discursivo? Isso já está sendo feito quando temos jovens negros e negras nos bancos acadêmicos, graças a políticas públicas na educação, pesquisando pensamento decolonial; isso está sendo feito quando biografias elencadas por professores e professoras aliadas na luta antirracista contemplam a diversidade crítica de raça e gênero; quando grupos de pesquisas são formados voltados à construção e disseminação de outras vozes. A partir de Paulo Freire, quando formula a teoria da conscientização, da qual parte para pensar o empoderamento, junto a feministas do Sul Global, como bell hooks, Rafia Zakaria, Srilatha Blatiwala, entre tantas outras, temos que o empoderamento por grupos oprimidos e silenciados nos leva a um cenário imprevisível, posto que nunca experimentamos as relações raciais nos termos que estão sendo estabelecidas nesse espaço no Brasil. 
ENTREVISTA Djamila Ribeiro: Uma voz para o nosso tempo
Christiane C. M. Fernandes | Deborah M. Guimarães | Juliana L. Sampaio | Rebeca F. de Melo

Seja onde chegaremos, sabemos que será em um cenário muito melhor e, cada vez mais, ninguém estará nem aí com Narciso.

5) Reconhecemos os esforços individuais de pessoas que lutam contra as formas institucionais e acadêmicas de silenciamento históricos e contra as tentativas de apagamento de epistemologias não hegemônicas. Também percebemos a importância de esforços coletivos e institucionais como, por exemplo, o que está sendo levado a cabo agora no Colégio Pedro II: a abertura de licenciaturas em humanidade integradas, que inclui um curso de filosofia, com enfoque em uma formação decolonial e com um currículo que privilegie os debates e as bibliografias que a tentativa de epistemicídio colonialista insistiu em silenciar. Contudo, a maioria dos cursos de filosofia no Brasil (e, em boa parte do mundo), ainda é quase exclusivamente focado na filosofia Ocidental. Sabemos que a tradição filosófica Ocidental é, com raríssimas exceções, eurocentrada, misógina, racista e colonialista. Por outro lado, na medida em que, como dissemos, nas Universidades brasileiras, nossos currículos são quase que absolutamente compostos pela Filosofia Ocidental, a maioria de nós estudou autores (geralmente, de fato, homens brancos) e correntes filosóficas dentro dessa tradição que foram/ são fundamentais na nossa formação e que abriram caminhos de pensamento profícuos, inclusive que nos possibilitaram criticar e questionar tal tradição e suas opressões. A partir dessa tensão, quais lhe parecem ser as estratégias ou a melhor maneira de nos relacionarmos com a tradição filosófica ocidental? Quais dificuldades você encontra(ou) ao propor diálogos entre a teoria feminista, a filosofia africana, por exemplo, e os pensadores mais comumente conhecidos como clássicos na filosofia ocidental? Aliás, como estabelecer esses diálogos?

Djamila Ribeiro: Um aluno de filosofia de primeiro ano vai perceber que o que é dito para ele como filosofia é aquilo que foi pensado na Grécia, na Alemanha e na França. É aquilo que foi pensado por homens desses lugares e que em nenhum outro lugar do mundo, em especial em nenhum outro lugar do Sul do Mundo, a filosofia foi pensada. Isso está posto na tradição filosófica dominante nesse país e é evidente que se trata de um ranço colonialista. Para quem pensa a partir de matrizes anticoloniais, não há sentido em dialogar com quem cultua esses valores, por serem produções formuladas por quem não tem suas humanidades reconhecidas. Agora, por que isso é um problema? Penso que precisamos pensar sempre no que Lélia González quis dizer quando escreveu "o lixo vai falar, e numa boa". Por que precisa haver o diálogo com Narciso? Veja, a única pessoa que Narciso escuta é Eco, uma ninfa condenada a dizer 
ENTREVISTA Djamila Ribeiro: Uma voz para o nosso tempo

apenas a última palavra que escuta. Assumir uma postura anticolonial é quebrar com a necessidade de aprovação e tutela do homem branco e da mulher branca, é falar por si e numa boa. Isso não significa, óbvio, que todo pensamento vindo da Europa seja descartável por si só. Ou seja, sou contra Europa como Centro, não sou contra pensamento de autores europeus. Estudei Beauvoir, entendo-a como brilhante. Estudar lugar de fala é entender e agir em desafio ao regime de autorização discursiva, valorizando a coexistência de vozes que somente não estão postas no debate por terem sido historicamente apagadas.

6) Em que medida a violência e a resistência vivenciada enquanto mulher negra foi importante para pensar as origens do racismo e as formas de combatê-lo na elaboração de seu último livro, o "Pequeno manual antirracista", publicado no final de 2019? Como compreender a questão que você coloca em sua dissertação de mestrado sobre qual é o sujeito que escreve e qual é o sujeito representado, a partir das demandas coletivas tão urgentes que se apresentam em nossa sociedade? Pensando inspirada no conceito de escrevivência de Conceição Evaristo, como uma espécie de formulação da importância de trazermos à tona nosso lugar de fala, como uma mulher negra acadêmica que escreve pode problematizar a tensão entre ser representante e representada do/no processo de afirmação identitária e de formação de subjetividade?

Djamila Ribeiro: Bom, penso que é necessário destacar que lugar de fala é diferente de representatividade. Claro que somos sujeitos marcados historicamente e que, a partir de nossas experiências em comum, enquanto grupo, será apresentado um outro mundo. No caso das mulheres negras, ser aquela que não está alocada em nenhum movimento, já que o movimento feminista historicamente foi um movimento branco e movimento negro trazia as reflexões e questões do homem negro, sua posição de forasteira de dentro, cunhada por Patricia Hill Collins, como aquela que tanto está dentro como está fora, é uma posição de solidão, mas também um lugar de potência já que observa a todos, enquanto não é observada.

Entretanto, sabemos bem que ser uma pessoa negra, por si só, não qualifica o indivíduo para falar sobre racismo. Aliás, muitas pessoas negras vão dizer que nunca sofreram racismo, que isso não existe, e sabemos bem o uso que é feito delas. Da mesma forma, é evidente que representatividade tem os seus limites, mas dentro deles existe sua importância para a autoestima da população negra, para a empregabilidade de pessoas negras e condições dignas de existência a famílias cujos ancestrais, muitas vezes, tiveram que vender o almoço para pagar o jantar. 
ENTREVISTA Djamila Ribeiro: Uma voz para o nosso tempo
Christiane C. M. Fernandes | Deborah M. Guimarães | Juliana L. Sampaio | Rebeca F. de Melo

Agora, lugar de fala não tem a ver com uma visão essencialista de que somente o negro pode falar de racismo, por exemplo. Lugar de fala implica numa postura ética de pensar o mundo a partir do lugar que se ocupa na matriz de dominação. Um debate estrutural que vai refletir, por exemplo, a alta taxa de encarceramento de homens negros, de feminicídio de mulheres negras, etc. Debater a questão leva a refletir sobre como o fato de pertencer a um grupo subalternizado faz com que esses indivíduos, estruturalmente falando, estejam sujeitos a determinadas violações de direitos humanos e falta de acesso a espaços de poder.

7) Angela Davis frequentemente afirma a necessidade de as pessoas serem mais do que não racistas, de serem antirracistas. Grada Kilomba, por sua vez, marca a diferença que deve existir entre os modos de lidar com o racismo por parte das pessoas brancas e por parte das pessoas negras, isto é, evidencia como o engajamento na luta antirracista precisa ser distinto para esses dois grupos. Você, em inúmeros textos, indica a necessidade de que as pessoas brancas lidem com racismo no viés da branquitude, o que implicaria, no caso dos estudos acadêmicos, por exemplo, em corpos brancos falando de si mesmos e seus lugares de privilégio, em vez de tomar o corpo negro na forma de objeto para análise. Essa posição, a ser tomada por parte das mulheres brancas, combateria tanto a atualização do binômio serva/senhora, denunciado pela bell hooks, bem como impediria o "extrativismo intelectual", tal como podemos, assinalado em "Ensinando a Transgredir": "agora as mulheres negras são colocadas na posição daquelas que atendem o desejo das brancas de saber mais sobre a raça e o racismo, de 'dominar' o tema. Curiosamente, a maioria das brancas que escrevem teorias feministas focadas na 'diferença' e na 'diversidade' não tomam a vida, o trabalho e as experiências das mulheres brancas como temas de suas análises de 'raça', mas enfocam, ao contrário, as mulheres negras ou mulheres de cor'. Você poderia falar um pouco sobre o "extrativismo intelectual" perpetrado por mulheres brancas acadêmicas?

Djamila Ribeiro: Muito interessante a pergunta. Quem tem o privilégio social acaba tendo o privilégio epistêmico e isso se verifica dentro dos movimentos feministas. Vozes autorizadas em face de vozes sufocadas atualizaram a tecnologia do racismo dentro do movimento feminista, no qual muitos saberes das mulheres negras acabam sendo apropriados, até hoje, por mulheres brancas sem que haja crédito ou reconhecimento financeiro para tanto. Trata-se de uma política genocida, pois, parafraseando Abdias do Nascimento em "O Genocídio do Negro Brasileiro", genocídio é todo aniquilamento físico, moral e intelectual de 
ENTREVISTA Djamila Ribeiro: Uma voz para o nosso tempo
Christiane C. M. Fernandes | Deborah M. Guimarães | Juliana L. Sampaio | Rebeca F. de Melo

um povo. Quando você silencia a voz de um grupo, você contribui para uma forma de morte desse grupo, como foi feito historicamente dentro dos movimentos feministas. Na atual quadra histórica, com mulheres negras liderando vendas de livros e estando na ponta da flecha da vanguarda, como sempre estiveram, o holofote que tanto iluminou mulheres brancas silenciadoras tornou-se uma fagulha mais fosca, pouco, muito pouco, perto da injustiça perpetrada desde os tempos das sinhás que choravam suas lamúrias pela frustrante vida amorosa com seus sinhôs, enquanto a mulher negra, que penteava seus cabelos durante a sessão não paga de terapia, tinha seus filhos arrancados de si e vendidos a outras fazendas para lucro da Casa. Pouco, mas o suficiente para manifestar o ranço daquelas que colocavam as escravizadas nos troncos por conta dos olhares tarados dos seus senhores. Hoje em dia, não me espantaria nem um pouco saber de um curso sobre interseccionalidade em alguma universidade ministrado por alguma neosinhá no qual a biografia não tenha nenhuma mulher negra. Seminários sobre o tema, sobre lugar de fala, com apenas uma mulher negra convidada. E vale dizer que muitas só falam do tema porque não podem mais ignorar, pois se pudessem o fariam solenemente, como fizeram durante a história. Lembro-me, na minha qualificação de mestrado, de uma acadêmica branca muito incomodada com meu trabalho. A certo momento, ela protestou "mas Sueli Carneiro já falou sobre feminismo negro, por que você precisa falar também?". Eram outros tempos, hoje duvido que ela fale algo dessa natureza. É evidente que existem mulheres brancas aliadas na luta, mas, os arranjos coloniais brasileiros mantêm-se, há séculos, estratificados, e ignorar esse fato seria uma tolice muito grande.

8) Bell hooks, em seu livro "Ensinando a transgredir", no capítulo intitulado "De mãos dadas com minha irmã", descreve a relação entre mulheres negras e mulheres brancas a partir da opressão histórica exercida por estas a aquelas, expressa no binômio serva/senhora. Por outro lado, reconhece a possibilidade da construção de uma relação igualitária entre mulheres brancas e mulheres negras desde que algumas condições sejam satisfeitas. Como, por exemplo, o reconhecimento inconteste dos pressupostos racistas que operam na forjação de subjetividade da mulher branca, bem como, a assunção de medidas reparadoras correlatas. Outro elemento que destaca é o pertencimento por parte das mulheres brancas à classe trabalhadora. Nas suas palavras: "pessoalmente percebo que muitas das minhas amizades e laços feministas mais profundos se formam com mulheres brancas que nasceram na classe trabalhadora ou pertencem à classe trabalhadora e compreendem o impacto da pobreza e da privação". Como você 
ENTREVISTA Djamila Ribeiro: Uma voz para o nosso tempo
Christiane C. M. Fernandes | Deborah M. Guimarães | Juliana L. Sampaio | Rebeca F. de Melo

observa essa intersecção entre raça e classe no que diz respeito à possibilidade da construção de uma relação simétrica entre mulheres brancas e mulheres negras? Que outros elementos você destacaria como condição de possibilidade para o estabelecimento de um laço feminista entre mulheres negras e mulheres brancas?

Djamila Ribeiro: Sem dúvida, a classe muitas vezes pode operar como um elemento de aproximação entre mulheres brancas pobres e mulheres negras. Parafraseando Simone de Beauvoir, as mulheres brancas vão ser solidárias dos homens brancos em vez das mulheres negras, enquanto as mulheres proprietárias serão dos homens proprietários e não das mulheres proletariadas. Muitas vezes, tal lógica opera a partir da construção da mulher como o Outro do homem, por funcionar não em si, mas em função dele.

Todas as questões estruturais à parte, penso que é possível mulheres brancas e negras se aliarem, mas quando, de fato, existe alteridade, isto é, enxergar a mulher negra como um sujeito. Grada Kilomba afirma que a mulher negra é a dupla antítese de branquitude e masculinidade, não é nem branca, nem homem, sendo posicionada em um lugar de muito mais difícil transcendência. Logo, a aliança deve partir da ciência desses lugares e da facilidade com a qual uma mulher branca pode se valer do sistema racista para apagar uma produção intelectual de uma mulher negra. Nesse sentido, gostaria de citar Audre Lorde quando diz que as ferramentas dos mestres não vão desmantelar a Casa grande. Uma aliança, portanto, somente é possível se houver transcendência pela mulher branca que se propuser aliada da torre no alto do castelo, onde ela, donzela, está para ser resgatada a bem de todo o povo. Isso é um desafio muito grande, e cabe às mulheres brancas, com compromisso ético na luta pela transformação social, fazê-lo.

9) No seu livro "Quem tem medo do feminismo negro?", você apresenta um texto publicado originariamente em 2015 na CartaCapital, intitulado "E se sua mãe tivesse te abortado?". Nele, você afirma que o Estado controla o corpo das mulheres, especialmente o das mulheres negras, e se posiciona em relação ao direito do aborto. Nós gostaríamos que você falasse um pouco acerca da nossa atual conjuntura política no que diz respeito a essa pauta tão cara às políticas feministas e fizesse uma análise comparativa entre o atual estado da questão aqui no Brasil e na América Latina.

Djamila Ribeiro: Sou a favor da descriminalização do aborto e penso que não cabe ao Estado legislar sobre os corpos das mulheres, como, de fato, não acontece com o homem. Estamos diante de um grave problema de saúde pública, 
ENTREVISTA Djamila Ribeiro: Uma voz para o nosso tempo

cuja raça e classe social operam um fator de desigualdade importante. Pesquisas de Debora Diniz, na Universidade de Brasília, indicam que uma a cada cinco mulheres terá feito aborto até os quarenta anos. Dados de 2015 apontam que 417 mil mulheres nas áreas urbanas do Brasil interromperam a gravidez, número que sobe para 503 mil se for incluída a zona rural. $\mathrm{O}$ acesso a procedimentos será um elemento diferenciado que pode significar vida ou morte, uma clínica na Zona Sul do Rio de Janeiro, ou uma agulha de crochê na mão de uma mulher negra, desesperada, sem dinheiro, orientação e outras condições materiais. Vale dizer que o aborto masculino é amplamente praticado e socialmente aceito: dados do Conselho Nacional de Justiça dão conta de 5,5 milhões de pessoas sem o nome do pai na certidão e mesmo quando está lá registrado, são 11,6 milhões de famílias brasileiras compostas somente por mães solos.

O texto que vocês mencionam foi um dos mais sensíveis que já escrevi, mas um dos mais importantes. Foi sobre uma conversa que tive com minha mãe quando ela colocou para fora e pôs-se a chorar ao me dizer que havia tentado meu aborto. Tratei de tranquilizá-la, disse que entendia a mulher negra, mãe de três crianças em sequência, sem dinheiro, sem espaço na casa, com a incerteza do relacionamento, tomar essa decisão. Disse ao final "Mãe, não há o que perdoar, o Estado sabe muito bem o que faz". O Estado patriarcal sabe que manter essa política de criminalização e de repressão sobre o corpo da mulher, muitas vezes, será o decisivo para que mais uma criança nasça no mundo repetindo o ciclo da pobreza e da falta de oportunidades à mãe, enquanto o pai não existe ou, se existe, está aí em algum lugar do mundo despreocupado. Sabe que muitas dessas mulheres que engravidam são crianças e adolescentes sob o jugo dos abusadores familiares ou do colega muito mais velho da vizinhança, que já a treina desde a mais tenra idade para ser uma mulher do seu lar, sem condições de se qualificar para uma vida melhor.

O debate que deveria ter avançado em governos progressistas, não avançou, e agora estamos numa situação inviável em termos de política pública brasileira. Quem sabe se não houvesse o golpe, quem sabe se a política brasileira tivesse seguido seu curso, talvez hoje estaríamos em outra mobilização, porém mera especulação. Na Argentina, um país cujo cenário político, com todos seus limites, transcorreu com menos atribulação que no Brasil, a pauta avançou e hoje está a um passo de ser regulamentada. Aqui, com esse governo absurdo que vivemos, não bastou a criminalização, como também houve o completo desmonte das políticas implementadas para mulheres. Em meio a isso, o movimento de mulheres segue resistindo e lutando por tempos melhores. 